\title{
Effects of Adding Intrathecal Magnesium Sulphate To Bupivacaine And Fentanyl in Lower Abdominal And Lower Limb Surgeries
}

\author{
Vishnuvardhan. $V^{1}$, Hemalatha. $S^{2 *}$, Sarika M Shetty ${ }^{3}$, Viswanathan.P.N ${ }^{4}$ \\ ${ }^{I}$ (Assistant Professor, Anaesthesiology, Sdumc, Kolar, India) \\ ${ }^{2}$ (Professor, Anaesthesiology, Jssmc, Mysore, India) \\ ${ }_{3}^{3}$ (Assistant Professor, Anaesthesiology, Jssmc, Mysore, India) \\ ${ }^{4}$ (Professor \& Ex-Hod, Anaesthesiology, Jssmc, Mysore, India)
}

\begin{abstract}
Background \& Aim: Addition of opiates with nonopioid adjuvants to local anaesthetics is becoming popular in perioperative pain management, as no single agent has yet been identified to specifically inhibit nociception without the usual side effects. Research continues concerning different techniques and drugs that could provide optimal operative conditions and postoperative pain relief. The present study is designed to assess the effectiveness of adding magnesium to a combination of intrathecal bupivacaine and fentanyl.

Methods: After obtaining informed consent, sixty patients randomized into two groups, thirty each. Study group received 0.5\% hyperbaric bupivacaine $2.5 \mathrm{ml}+25 \mathrm{mcg}(0.5 \mathrm{ml})$ fentanyl $+50 \mathrm{mg}(1 \mathrm{ml})$ magnesium sulphate. Control group received $0.5 \%$ hyperbaric bupivacaine $2.5 \mathrm{ml}+25 \mathrm{mcg}(0.5 \mathrm{ml})$ fentanyl $+1 \mathrm{ml}$ of preservative free $0.9 \%$ sodium chloride. Time of onset of sensory, motor block, maximum level of sensory block, time to attain the same, duration of analgesia, two segment regression time, time for complete motor recovery, haemodynamic parameters and perioperative complications studied. All the statistical methods were carried out through the SPSS for Windows (version 16.0). Descriptive statistics, frequencies, crosstabs, independent sample t- test and repeated measures ANOVA were the statistical methods used for this study.

Results: Duration of analgesia, time for two segment regression \& time for complete motor recovery is significantly longer in $\mathrm{MgSO}_{4}$ group than in control group. Onset time for sensory and motor blockade is delayed in $\mathrm{MgSO}_{4}$ group but is statistically non-significant.

Conclusion: Addition of intrathecal magnesium provides longer duration of analgesia, longer time for two segment regression \& delays time for complete motor recovery with no significant haemodynamic variations/side effects.
\end{abstract}

Keywords: Adjuvants, analgesia, bupivacaine, fentanyl, intrathecal, magnesium sulphate

\section{Introduction}

Effective treatment of perioperative pain represents an important component of postoperative recovery as it serves to blunt autonomic, somatic and endocrine reflexes with a resultant potential decrease in perioperative morbidity.[1]

Research continues concerning different techniques and drugs that could provide optimal operative conditions and postoperative pain relief. Various groups of drugs such as opiates, benzodiazepines, ketamine, alpha 2 agonists such as clonidine, dexmedetomidine etc, are being used clinically as adjuvants in subarachnoid block, yet no drug has been identified that specifically inhibits nociception without associated side effects.

Techniques involving the smaller doses of opioid in combination with nonopioid adjuvant drugs are becoming increasingly popular approaches for perioperative pain management. Noxious stimulation leads to release of glutamate and aspartate neurotransmitters, which bind to various subclasses of excitatory amino acid receptors, including the N-methyl D-aspartate (NMDA) receptor. Activation of NMDA receptors leads to calcium and sodium influx into the cell, with an efflux of potassium and initiation of central sensitization and wind-up.[2,3] NMDA receptor signaling may be important in determining the duration and intensity of postoperative pain. Magnesium blocks NMDA channels in a voltage-dependent way, and the addition of magnesium produces a reduction of NMDA-induced currents.[4] Thus it has antinociceptive effect and has application in anaesthesia. It has various actions such as analgesia, vasodilation by calcium block, and inhibition of catecholamine release. It is worthwhile to study the role of supplemental magnesium in providing perioperative analgesia, because this is a relatively harmless molecule, economical and also because the biological basis for its potential antinociceptive effect is promising.[5] The safety of intrathecal magnesium administration has been evaluated and established as an effective adjuvant to bupivacaine.[6,7] The safety profile has been evaluated, including histopathological analysis.[8] 
The aim of this study was to evaluate the effects of intrathecal supplementation of magnesium sulphate to bupivacaine-fentanyl in patients undergoing lower limb and lower abdominal surgeries.

\section{Materials And Methods}

After approval of the institutional ethical committee and obtaining written informed consent, sixty patients undergoing elective lower abdominal or lower limb surgeries of ASA grade I and II between 20 to 60 years were enrolled in this study. Patients allergic to local anaesthetics, having local infections, bleeding disorders, cardiovascular diseases, Seizure disorder, Neuropsychiatric disorders, kyphoscoliosis and spondylosis were excluded from the study. It is a double blinded comparative study with simple random sampling technique. Sixty patients were divided into two groups of thirty each.

All patients were fasted for a minimum of eight hours preoperatively and after gaining IV access, preloaded with Ringers lactate $(10 \mathrm{ml} / \mathrm{kg})$. Standard ASA monitors were connected and basal parameters noted. The lumbar subarachnoid block was performed under strict aseptic precautions with the patients in either left or right lateral position with pillow under the head and table flat. Lumbar dural tap was done in the L3-L4 interspace, midline approach, using 25 gauge Quincke's needle after local infiltration of skin with $2 \%$ Lignocaine. Magnesium sulphate $1 \mathrm{ml}(500 \mathrm{mg})$ was taken and diluted to $10 \mathrm{ml}$ with $0.9 \%$ normal saline, of which $1 \mathrm{ml}$ (50mg) was taken in to a separate syringe.

Group M (study group) received $2.5 \mathrm{ml}$ of $0.5 \%$ bupivacaine(Heavy) $+25 \mu \mathrm{g}(0.5 \mathrm{ml})$ fentanyl, immediately followed by $50 \mathrm{mg}(1 \mathrm{ml})$ magnesium sulphate and Group S (control group) received $2.5 \mathrm{ml}$ of $0.5 \%$ bupivacaine $($ Heavy $)+25 \mu \mathrm{g}(0.5 \mathrm{ml})$ fentanyl, immediately followed by $1 \mathrm{ml}$ of $0.9 \%$ sodium chloride.

After obtaining free and clear flow of CSF, drug was administered slowly, making sure of negative aspiration for blood. Patients were made to lie supine immediately after the completion of injection. The time of completion of injection of drug was recorded as 0 minute. Heart rate, NIBP, ECG and pulse oximeter were used for intraoperative monitoring. Oxygen supplementation at $5 \mathrm{~L} / \mathrm{min}$ through face mask was given for all patients.

Onset of sensory block was taken as time between the end of injection of intrathecal anaesthetic and the absence of pain at T12 dermatome and assessed by pin prick test. Motor block was assessed by modified Bromage scale (0- no motor loss; 1-inability to flex the hip; 2- inability to flex the knee; and 3- inability to flex the ankle). Onset of motor block was taken as the time from intrathecal injection to Bromage 1 block and duration of motor block was taken as time from the onset of motor block till the Bromage score becomes zero. Assessment of pain was done by Visual analogue scale (VAS) - 10cm horizontal line was drawn, no pain at left end (0) and severe pain at right end (10). The score is the distance in centimeters from left side of the scale to the mark shown by the patient. Time for first rescue analgesia was taken from the time of intrathecal injection to a VAS $>4$, at which rescue analgesia in the form of inj.diclofenac slow IV was administered.

Patients were monitored for intraoperative complications like hypotension, bradycardia, shivering, nausea and vomiting. Then shifted to recovery area after completion of surgery and then to postoperative ward and observed. They were followed up for 24 hours for any postoperative complications.

Hypotension: taken as a decrease in systolic blood pressure by $25 \%$ of baseline value or systolic blood pressure $\leq 90 \mathrm{mmHg}$. Treated with rapid infusion of intravenous fluids, increasing oxygen supplementation through face mask, Inj. mephentermine $6 \mathrm{mg}$ iv increments and Inj. atropine $0.6 \mathrm{mg}$ iv if associated with bradycardia. Bradycardia is taken as $\geq 25 \%$ decrease in heart rate compared to baseline value or if heart rate $<60 /$ minute.

Descriptive statistics, frequencies, crosstabs, independent sample t- test and repeated measures ANOVA were the statistical methods used for this study.

\section{Results, Figures \& Tables}

There were no significant differences between the two groups in age, sex, weight, height, and duration of surgery (Table 1).

Heart rate \& Mean Arterial Pressures between the two groups were similar and are shown in figure $1 \&$ 2 respectively. Oxygen saturations remained stable, and there were no significant differences between the two groups.

There was significant delay in time for two segment regression between the study and control groups, $171.33 \pm 33.34$ minutes and $129.5 \pm 24.99$ minutes respectively, with $\mathrm{p}$ value $=.00$. Time for complete motor recovery was also delayed significantly between the two groups, study group ( $286 \pm 55.42$ minutes) and control group $(227.83 \pm 38.54$ minutes with $\mathrm{p}$ value of 0.00$)$ (Table 2$)$. Though onset of sensory and motor block were delayed in study group compared to control group, they were statistically insignificant. (Table 2)

Duration of analgesia in study group was significantly delayed $290 \pm 103.64$ minutes when compared to control group $210 \pm 56.03$ with p value of .00 . Mean VAS scores were significantly less in study group when compared to control group. There was wide difference noted in the VAS scores between the two groups after 1 hour in the postoperative period (Fig. 3) 
As shown in table 3, there were no significant differences in terms of intraoperative and postoperative complications between the two groups. In study group there was one case with ventricular premature complexes intraoperatively which was successfully treated with Inj. preservative free lignocaine $1 \mathrm{mg} / \mathrm{kg} \mathrm{I.V}$. No patients in either group had any motor or sensory complications identified till the discharge and further follow up to the hospital.

Table 1. Demographic data for the two groups

\begin{tabular}{|l|c|c|c|}
\hline & Study group $(\mathrm{n}=30)$ & Control group $(\mathrm{n}=30)$ & $\mathrm{p}$ value \\
\hline Age(years) & $42.73 \pm 12.22$ & $41.66 \pm 11.98$ & .734 \\
\hline Sex(F/M) & $10 / 20$ & $12 / 18$ & .069 \\
\hline Weight $(\mathrm{Kg})$ & $59.96 \pm 8.68$ & $60.56 \pm 8.81$ & .791 \\
\hline Height $(\mathrm{cm})$ & $162.90 \pm 8.02$ & $162.46 \pm 6.90$ & .823 \\
\hline Duration of surgery(min) & $99.16 \pm 32.56$ & $93.66 \pm 32.82$ & .517 \\
\hline
\end{tabular}

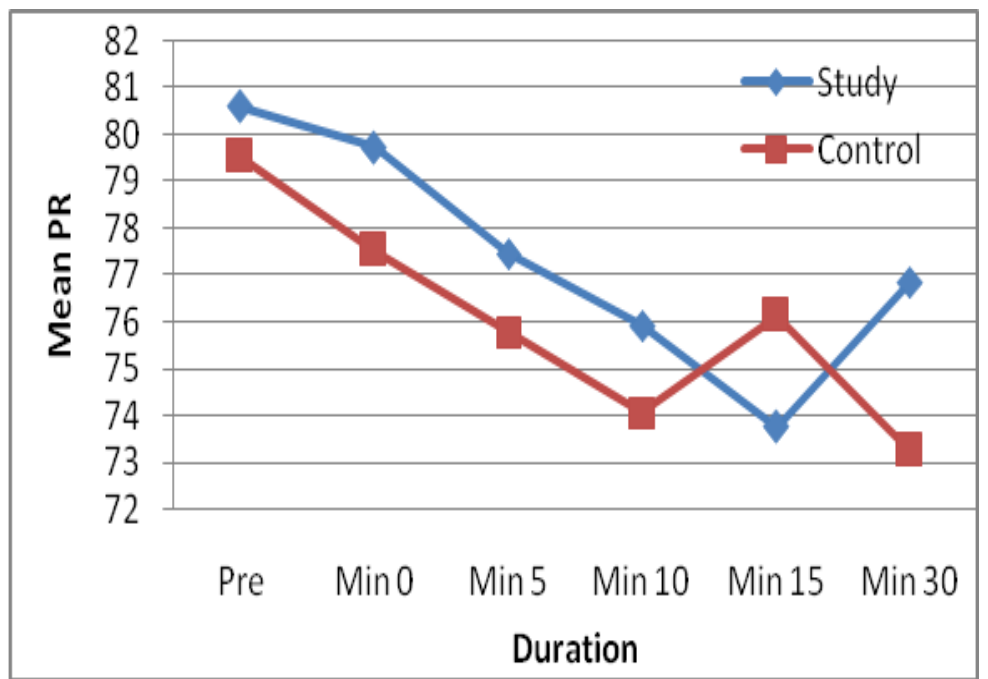

Figure 1. Mean Pulse Rate

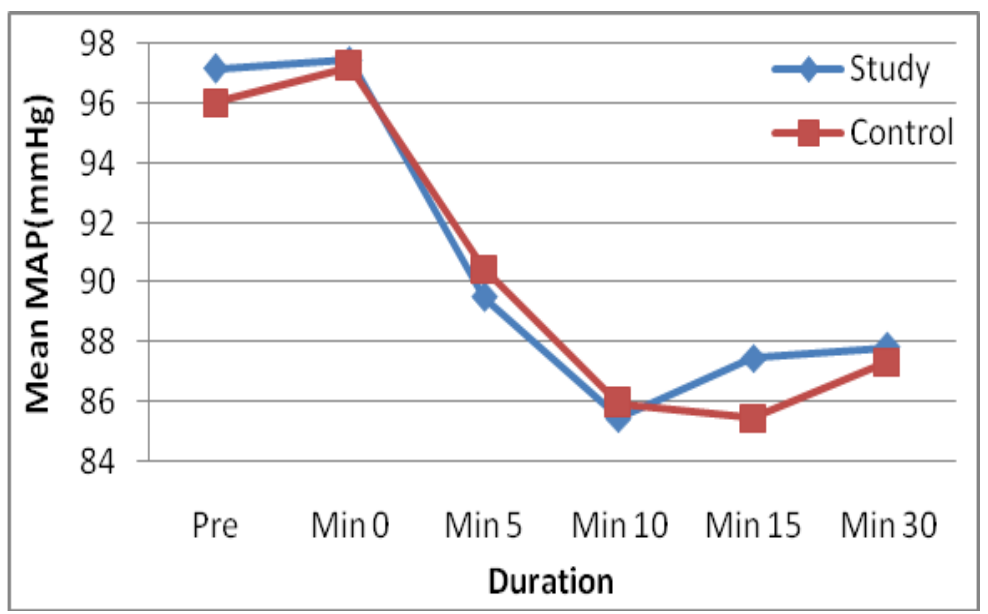

Figure 2. Mean of mean arterial pressure

Table 2. Characteristics of Subarachnoid block

\begin{tabular}{|l|c|c|c|}
\hline Sensory block & Study group & Control group & p value \\
\hline Onset of sensory blockade(min) & $1.92 \pm .74$ & $1.80 \pm .65$ & 0.490 \\
\hline Maximum level of sensory blockade & $6.53 \pm 1.27$ & $7.13 \pm 1.13$ & .060 \\
\hline Time to reach highest dermatomal level(min) & $3.8 \pm 1.2$ & $3.78 \pm .79$ & .950 \\
\hline Two segment regression time & $171.33 \pm 33.34$ & $129.5 \pm 24.99$ & .00 \\
\hline Motor block & & & \\
\hline Onset of motor blockade & $2.35 \pm 1.4$ & $2.23 \pm .87$ & .701 \\
\hline Time for complete motor recovery & $286 \pm 55.42$ & $227.83 \pm 38.54$ & .00 \\
\hline Duration of analgesia & $290 \pm 103.64$ & $210 \pm 56.03$ & .00 \\
\hline
\end{tabular}




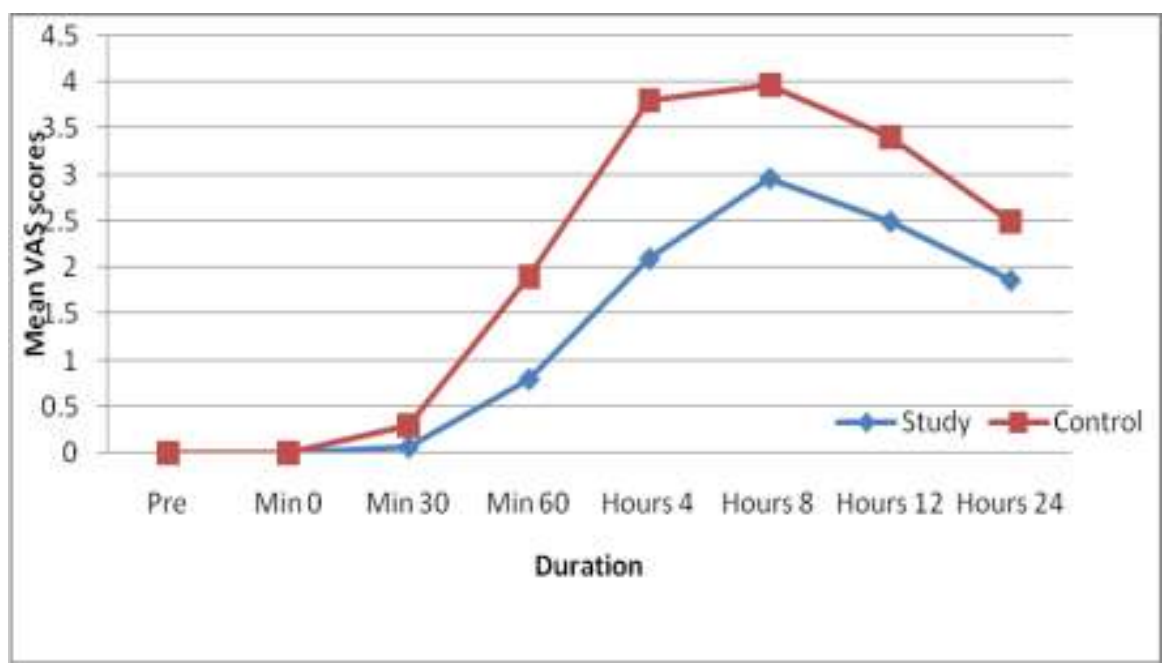

Figure 3. Mean VAS score

Table 3. Side effects

\begin{tabular}{|l|c|c|}
\hline & Study group & Control group \\
\hline Hypotension & $3(10 \%)$ & $3(10 \%)$ \\
\hline Bradycardia & $5(16.6 \%)$ & $4(13.3 \%)$ \\
\hline Ectopics & $1(3.3 \%)$ & $0(0 \%)$ \\
\hline Shivering & $1(3.3 \%)$ & $1(3.3 \%)$ \\
\hline Nausea & $1(3.3 \%)$ & $0(0 \%)$ \\
\hline Vomiting & $0(0 \%)$ & $1(3.3 \%)$ \\
\hline Itching & $1(3.3 \%)$ & $1(3.3 \%)$ \\
\hline
\end{tabular}

\section{Iv. Discussion}

Subarachnoid block is a commonly employed anaesthetic technique for performing lower abdominal and lower limb surgeries. It is a safe, inexpensive and easy-to-administer technique. It is simple, has rapid onset and is reliable. The risk of general anaesthesia and mishaps due to airway management are avoided by this technique.[9] Various additives are being administered to prolong the anaesthesia and analgesia provided by this technique.

The present study has found that magnesium sulphate administered intrathecally is effective in prolonging bupivacaine fentanyl anaesthesia. There are no statistically significant differences in terms of demographic properties or ASA grading. The mean age, weight, height, gender, type of surgeries, duration of surgery are comparable in both the groups. There was significant delay in the onset time for sensory block in magnesium group in the studies conducted by Shukla et al (study group: $6.46 \pm 1.33 \mathrm{~min}$, control group: $4.14 \pm$ $1.06 \mathrm{~min}$ ) and Nath et al (study group: $10.1 \pm 2.0 \mathrm{~min}$, control group 5.2 $\pm 1.1 \mathrm{~min}$ ) but in the present study though there is delay in magnesium group it is statistically insignificant.[10, 11]

In the study done by Sanad et al (study group: $4 \pm 0.5 \mathrm{~min}$, control group: $3.2 \pm 0.8$ ) though there was delay in onset time but was comparable between two groups which is similar to our study.[12] The shorter onset time when compared to other studies can be attributed to a lower dermatomal level (T12) considered in our study, Shukla et al (T10) and in Nath et al (T8).[10, 11]

There is no significant difference in the maximum level of sensory block attained between the two groups. This was also observed by Jong Wha Lee et al(T6), Dayioglu H et al(T7) and Sanad et al(T107). $[12,13,14]$ There is no significant difference in time taken to reach highest dermatomal levels in between the two groups. This is supported by H. Dayioglu et al (study group: $21.5 \pm 4.5 \mathrm{~min}$, control group: $22.9 \pm 5 \mathrm{~min}$ ). [14] In the present study, patients who received magnesium had a delay in mean onset of motor block than those in control group but this was not statistically significant. There was delay in onset of motor block in studies done by Shukla et al (study group: 7.18 $\pm 1.38 \mathrm{~min}$, control group: $4.81 \pm 1.03$, Nath et al (study group: 16.18 min, control group: $14.30 \mathrm{~min}$ ), and Malleeswaran et al (study group: $5.7 \pm 0.7 \mathrm{~min}$, control group: 5.1 \pm 1.0 ).[6,10,11]

The above mentioned studies considered modified Bromage scale 3 for the onset of motor block; this could be the reason for the increased duration noted in these studies which was significant. The delay could have been better appreciated between the two groups in the present study if the progression of block from modified Bromage scale 1 to 3 had been studied.

The time for two segment regression of sensory block was taken as the time taken for the sensory level to regress by two segments. In the present study the mean time in study group is 171.33 minutes and 129.50 minutes in control group. There is significant delay in the magnesium group which is supported by the study of 
H. Dayioglu et al, in which they found time for two segment regression in study group as $58.9 \pm 22.8$ minutes and in control group as $44.7 \pm 18.9$ minutes. Less time required for two segment regression in the study by $\mathrm{H}$. Dayioglu et al might be because of the less concentration of bupivacaine $(6 \mathrm{mg})$ used in their study.[14]

The duration of analgesia or time to rescue analgesia was the time at which patient requested first analgesic. The mean time to rescue analgesia in the present study is 290 minutes in study group and 210 minutes in control group. This was found to be statistically significant and is supported by Nath et al(study group: 291.4 min, control group: $263.9 \mathrm{~min}$ ) and Malleeswaran et al(study group: $229.3 \mathrm{~min}$, control group: $187.7 \mathrm{~min}$ ). [6,11] The mean time for complete motor recovery in the present study is 286 minutes in study group and 227.83 minutes in control group. This is statistically significant. Malleeswaran et al (study group: 200 min, control group: $175.3 \mathrm{~min}$ ), and study done by Jehad Ahmed Sayed (study group: $205 \mathrm{~min}$, control group: $165 \mathrm{~min}$ ) also found the similar result of significant delay in time for motor recovery in study group.[6,15]

There were no significant changes in the mean pulse rate and mean arterial pressures between the two groups in the present study. This was comparable with the findings of Nath et al, Sanad H et al, Malleeswaran S et al, Jabalameli $\mathrm{M}$ et al, and Shukla et al.[6,10,11,12,16] No significant differences were seen in the intraoperative and postoperative complications, also noted by Sanad et al and Malleeswaran et al.[6,12]

\section{Conclusion}

In patients undergoing lower abdominal and lower limb surgeries, addition of $50 \mathrm{mg}$ of magnesium sulphate to the combination of intrathecal bupivacaine and fentanyl provides longer duration of analgesia, longer time for two segment regression, delays time for complete motor recovery without significant haemodynamic variations and side effects.

However further studies should also explore whether the addition of magnesium can reduce the intrathecal dose requirement of local anaesthetic agents, and possibly even replace fentanyl, thereby avoiding opioid side effects such as sedation, pruritus and respiratory depression.

\section{References}

[1] Sirvinskas E, Laurinaitis R: Use of magnesium sulphate in anesthesiology. Medicina 2002;38:695-8

[2] Woolf CJ, Thompson SW. The induction and maintenance of central sensitization is dependent on N-methyl D-aspartic acid receptor activation: Implications for the treatment of post-injury pain and hypersensitivity states. Pain 1991;44:293-9.

[3] Woolf CJ, Chong MS. Preemptive analgesia: Treating postoperative pain by preventing the establishment of central sensitization. Anaesthesia Analgesia 1993;77:362-79.

[4] Ascher P, Nowak L. Electrophysiological studies of NMDA receptors. Trends Neurosci 1987; 10:284-88

[5] Lysakowsi C, Dumont L, Czarnetzki C, Tramer MR. Magnesium as an adjuvant to postoperative analgesia: A systemic review of randomized trial. Anaesthesia analgesia 2007;104:1532-9.

[6] Malleeswaran S, Panda N, Mathew P, Bagga R. A randomized study of magnesium sulphate as an adjuvant to bupivacaine in patient with mild preeclampsia undergoing caesarean section, International Journal of Obstetric Anaesthesia 2010;19:161-166.

[7] Bilir A, Gulec S, Erkan A, Ozcelik A. Epidural magnesium reduces postoperative analgesic requirements, British Journal of Anaesthesia 2007;98:519-523.

[8] Chanimov M, Cohen ML, Grinspun Y, Herbert M, Reif R, Kaufman I, et al. Neurotoxicity after spinal anaesthesia induced by serial intrathecal injections of magnesium sulphate. An experimental study in a rat model. Anaesthesia 1997;52:223-228.

[9] Miller RD, Erikrson LL, Fleisher LA. Anaesthesia for Obstetrics. In: Birnbach DJ, Browne IM, editors. Miller's anaesthesia. $7^{\text {th }}$ ed. (New York: Churchill Elsevier); 2005:2203-2240.

[10] Shukla D, Agarwal AV, Pandey HD, Tyagi C. Comparative study of dexmedetomidine with intrathecal magnesium sulphate used as adjuvant to bupivacaine. Journal of anaesthesiology clinical pharmacology, 2011;27:495-499.

[11] Nath MP, Garg R, Talukdar T, Choudhary D, Chakrabarty A. To evaluate the efficacy of intrathecal magnesium sulphate for hysterectomy under subarachnoid block with bupivacaine and fentanyl: A prospective randomized double blind clinical trial. Saudi Journal of Anaesthesia, 2012; 6:254-258.

[12] Sanad H, Abdelsalam T, Hamada M, Alsherbiny MA. Effects of adding magnesium sulphate, midazolam or ketamine to hyperbaric bupivacaine for spinal anaesthesia in lower abdominal and lower extremity surgery. Ain shams journal of anaesthesiology 2010; 3:43-52.

[13] Lee JW, Kim MK, Shin YS, Nyeo B. The analgesic effect of single dose of intrathecal magnesium sulphate, Korean Journal of Anesthesiology 2007;52:72-76.

[14] Dayioglu H, Baykara ZN, Salbes A, Solak M, Toker K. Effects of adding magnesium to bupivacaine and fentanyl for spinal anaesthesia in knee arthroscopy. Journal of Anaesthesia 2009;23:19-25.

[15] Sayed JA, Fathy MA. Maternal and Neonatal Effects of Adding Two Different Doses of Intrathecal Magnesium Sulphate to Bupivacaine Fentanyl Spinal Anaesthesia in Mild Preeclamptic Patients Undergoing Caesarean Section. Journal of American Science 2012;8:435-441

[16] Jabalaneli M, Pakzadmoghadam SH. Adding different doses of intrathecal magnesium sulphate for spinal anaesthesia in cesarean section: A prospective double blind randomized trial. Advanced Biomedical Research 2012;1:1-6. 